\title{
Las transferencias de aprovechamientos urbanísticos
}

\section{Sebastián Olmedo Pérez}

\section{LAS TRANSFERENCIAS DE APROVECHAMIENTOS URBANÍS- TICOS Y LAS DIFERENTES SUBCATEGORÍAS DEL SUELO UR- BANO NO CONSOLIDADO}

\section{Introducción y antecedentes}

La Ley 7/2002 de Ordenación Urbanística de Andalucía (LOUA) vuelve a dar carta de naturaleza a las Transferencias de Aprovechamientos Urbanísticos (TAU).

La LOUA vuelve a recoger esta técnica urbanística dirigida a incorporar el principio de compensación de beneficios y cargas en el suelo urbano, pero con un alcance restringido con respecto a sus antecedentes (TRLS 1992) y con una regulación deficiente, contenida en el art.62 de la LOUA, que no ayuda a su clarificación conceptual y que sin duda va a dificultar su efectiva implantación.

Que la LOUA contiene una regulación deficiente de las TAU, se pone de manifiesto principalmente en el hecho de que el art.62 de la misma -que es el precepto específico en el que se establece la regulación de esta técnica urbanística- no especifique el ámbito de su aplicación; es decir, en qué clase y categoría de suelo puede presentarse y cuáles son los presupuestos de gestión urbanística para su aplicación.

En efecto, el apartado 1 del art.62 de la LOUA únicamente describe en qué consiste las TAU y sus efectos:

“... los propietarios de una parcela o solar pueden transferir el aprovechamiento subjetivo que les corresponda y no puedan materializar en una u otro, a otras parcelas o solares en situación inversa, es decir, que tengan atribuido un aprovechamiento objetivo superior al que corresponda a sus propietarios. La transferencia determina la justa distribución del aprove- 
chamiento objetivo entre los propietarios intervinientes y legitima su materialización por éstos".

Como puede comprobarse, este primer apartado del art.62 de la LOUA no especifica en qué clase y categoría de suelo tienen que encontrarse esas parcelas o solares susceptibles de ser objeto de transferencias. Pero tampoco del resto de apartados de ese art.62 se concretan los presupuestos de aplicación desde el punto de vista de gestión urbanística, pues se dedican a regular los requisitos procedimentales para su validez y eficacia.

Además la regulación de la LOUA es deficiente, por incorporar el término de solar, que hace referencia a un concepto de parcela apta para la edificación en el suelo urbano definitivamente consolidado, categoría de suelo urbano en la que es muy dudosa la posibilidad de incorporación de los mecanismos de las TAU.

Por último, es una regulación deficiente, por el encuadre sistemático que realiza la LOUA de las TAU en el Título II de la misma.

A continuación se intenta realizar una aproximación a un estudio sistemático de la completa regulación de las TAU que se deducen de otros preceptos de la LOUA con la finalidad de clarificar su alcance y efectos. De igual modo, el estudio de las TAU pone de manifiesto las diferentes subcategorías del Suelo Urbano No Consolidado, y de las que se deriva un régimen jurídico de derechos y deberes diferenciados.

\section{PRESUPUESTOS PARA LA EXISTENCIA DE LAS TRANSFEREN- CIAS DE APROVECHAMIENTOS URBANÍSTICOS}

\subsection{La necesaria cobertura en el planeamiento urbanístico}

Lo primero que habrá que manifestar, es que la existencia de las TAU depende de una decisión de planeamiento.

Según el artículo 62.1 de la LOUA, la técnica de las Transferencias se aplicarán "si así lo previera el instrumento de planeamiento aplicable".

Por tanto, no es una técnica urbanística de existencia necesaria en ninguna clase de planeamiento, ni siquiera para los municipios de relevancia territorial. Así, no se configura como determinación estructural o pormenoriza- 
da de carácter necesaria para el planeamiento general en el art.10 de la LOUA, sino que dependerá de la estrategia de gestión adoptada por el planeamiento para la ejecución de sus previsiones.

La LOUA no predetermina qué clase de instrumento de planeamiento es el legitimado para adoptar la decisión de aplicación de las TAU ("el instrumento de planeamiento aplicable").

En principio, y desde la redacción literal del art.62.1 de la LOUA, podría interpretarse en un sentido amplio, y entender que se encontrarían legitimados para ello todos los instrumentos de planeamiento urbanístico ("el aplicable"). Pero como podrá comprobarse, esta primera conclusión no es acertada siendo necesario reconducir esta primera interpretación desde criterios finalistas y sistemáticos.

Desde una interpretación finalista, se produce una primera restricción del alcance del art. $62.1 \mathrm{Y}$ es que por el objetivo específico de esta técnica (conseguir dotaciones en el suelo urbano) es preciso reconocer que esta decisión de aplicabilidad de la técnica de las TAU debe estar reservada a los instrumentos de ordenación del suelo urbano no consolidado: el Planeamiento General (Plan General y Plan Intermunicipal) y el Plan Especial de Reforma Interior.

Pero además, habrá que introducir una segunda limitación que impide las posibilidades de que un Plan Especial de forma autónoma, y sin cobertura en las previsiones del Plan General, pueda llegar a establecer directamente la aplicación de las TAU. Y es que, como se verá, la aplicación de las TAU exige la determinación de un aprovechamiento medio, que es una previsión que únicamente pueden establecer los instrumentos de planeamiento general. Por tanto, para que un Plan Especial pueda establecer la aplicación de las TAU a un ámbito debe contar con la previa habilitación del Plan General, único facultado para establecer la determinación previa necesaria para que pueda aplicar las TAU: la delimitación de un área de reparto. Por consiguiente, sólo puede haber TAU allí donde el Plan General lo determine directamente o remita esta decisión al Plan Especial, estableciendo en el propio Plan General, el presupuesto necesario: la delimitación del área de reparto.

\section{2 Ámbito de aplicación de las TAU}

2.2.1. La necesidad de una previa delimitación de un área de reparto y del establecimiento de un aprovechamiento medio

No obstante la indeterminación del apartado 1 del art.62 de la LOUA sobre el ámbito de aplicación de esta técnica, del mismo puede deducirse (táci- 
tamente) que para que puedan operar las TAU se precisa el establecimiento de un aprovechamiento medio y por tanto de un Área de Reparto.

Estas determinaciones urbanísticas de planeamiento son necesarias para que puedan existir parcelas susceptibles de ser objeto de transferencias, es decir, que se presente el presupuesto de hecho contemplado en el propio precepto: dos parcelas en situación inversa respecto a un aprovechamiento subjetivo similar, una parcela a la que le corresponda un aprovechamiento subjetivo que no pueda materializar por ausencia completa o incompleta de aprovechamientos reales suficientes, y otra, con un aprovechamiento objetivo superior al subjetivo.

Si no existe área de reparto, no puede determinarse un derecho patrimonializable en función de un aprovechamiento medio, y en consecuencia, no pueden existir parcelas en situación inversa, pues cada parcela sería un ámbito autónomo de atribución de aprovechamientos.

\subsubsection{Inexistencia de unidades de ejecución}

Conjuntamente con este presupuesto lógico (es decir, la previa existencia de un Área de reparto y determinación del aprovechamiento medio de la misma), para que puedan aplicarse las Transferencias se requiere de otra condición previa: la inexistencia de unidades de ejecución. Porque las TAU y las unidades de ejecución cumplen funciones similares (la justa distribución de beneficios y cargas) por lo que si se ejecuta el Plan mediante Unidades de Ejecución no puede aplicarse las TAU, que tienen, así carácter subsidiario.

Si existe unidad de ejecución no procede la aplicación de las TAU sino del sistema de actuación mediante el que se debe ejecutar de forma integrada la ordenación contenida en su ámbito, ya sea el de compensación, cooperación o expropiación.

\subsection{3 categoría de suelo: presencia exclusiva en suelo urbano no consolidado}

El dato conjunto de los presupuestos anteriormente descritos requeridos para pueda entrar en juego las TAU (la existencia de parcelas con usos lucrativos, su inclusión en Área de Reparto para que pueda tener establecido un aprovechamiento medio, y su exclusión de los ámbitos delimitados de unidades de ejecución) nos permite llegar a otro conclusión, y es que la concurrencia de todos esos presupuestos sólo puede darse en una clase y categoría de suelo determinada: el suelo urbano no consolidado. 
En efecto, en suelo urbanizable todos los terrenos (excepto, de forma facultativa los Sistemas Generales) deben quedar incluidos en unidades de ejecución. Siempre que el Plan establezca una calificación de uso lucrativo en el suelo urbanizable, ese terreno tiene que pertenecer una unidad de ejecución. Por tanto, en el suelo urbanizable no es posible aplicar las Transferencias de Aprovechamientos Urbanísticos.

\section{Las Transferencias sólo pueden aplicarse en suelo urbano, y dentro de es- ta clase, exclusivamente en la categoría de no consolidado.}

Esta conclusión, se ve confirmada por el resto de preceptos de la LOUA que de forma desperdigada aluden a las Transferencias: en concreto, el art.143.2.c y el art.55.2.

Así, el art.143.2 c) de la LOUA alude a las TAU como modo de adquisición de dotaciones públicas en suelos urbanos no consolidados no integrados en Unidades de Ejecución.

Artículo 143. Las actuaciones urbanizadoras no integradas

1. Cuando no esté prevista en el planeamiento urbanistico ni se efectúe por el municipio delimitación de unidades de ejecución, la ejecución del planeamiento, salvo la edificación, se llevará a cabo mediante obras públicas ordinarias, de acuerdo con la legislación que sea aplicable por razón de la Administración Pública actuante.

2. El suelo preciso para las dotaciones se obtendrá en el supuesto previsto en el apartado anterior por:

a) Cesión obligatoria y gratuita, en virtud, en su caso, de reparcelación.

b) Cesión gratuita en virtud de convenio urbanístico.

c) Transferencias de aprovechamiento urbanistico en suelos urbanos no consolidados no integrados en unidades de ejecución.

d) Adquisición por expropiación, compra o permuta.

Y por último, el art.55.2 de la LOUA que regula el régimen del suelo urbano no consolidado no incluido en unidades de ejecución, distinguiendo dos supuestos en atención a la presencia o inexistencia de delimitación de área de reparto.

Este precepto dispone en su apartado A párrafo segundo que las cesiones de suelo son las mismas prescritas "para el suelo urbanizable en el artículo anterior, si bien la de superficie de suelo ya urbanizada precisa para materializar el aprovechamiento lucrativo correspondiente a la participación del Munici- 
pio será del diez por ciento del aprovechamiento medio del área correspondiente, o en caso de no estar incluidos los terrenos en ningún área de reparto, del aprovechamiento objetivo que tuvieran asignado..."

En su apartado B, el art.55.2 dispone que los propietarios de esta clase de suelo (urbano no consolidado no incluido en unidad de ejecución) tienen derecho al noventa por ciento del aprovechamiento medio del área de reparto o, "en otro caso, al noventa por ciento del aprovechamiento objetivo".

Por tanto, se comprueba que en este apartado B del art.55.2 que regula el régimen del suelo urbano no consolidado no incluido en unidad de ejecución se establece una subdivisión, en atención a la presencia o no de una determinación del planeamiento general: la delimitación de un área de reparto.

Esta conclusión se ve confirmada y ratificada igualmente en el párrafo segundo de este apartado B, que dispone que para materializar el aprovechamiento "al que alude el párrafo anterior" (que no es otro que el aprovechamiento subjetivo, es decir el $90 \%$ del aprovechamiento medio, o en su caso, del objetivo), podrá autorizarse la edificación aún cuando la parcela correspondiente no tenga todavía la condición de solar", siempre que se cumplan una serie requisitos, entre otros:

a) La cesión del suelo correspondiente al aprovechamiento urbanístico imputable al Municipio por razón de su participación en las plusvalías y "la adquisición, en su caso, mediante transferencias de aprovechamientos, de los excedentes de aprovechamientos o sus equivalentes económicos."

En consecuencia, las Transferencias de Aprovechamientos Urbanísticos se aplican en el suelo urbano no consolidado no incluido en unidades de ejecución. Pero no en todos los casos de este suelo (urbano no consolidado) en los que no existan unidades de ejecución pueden aplicarse las TAU, de ahí la expresión "en su caso". Sólo es posible aplicar las TAU allí donde existan excedentes de aprovechamiento por encima del aprovechamiento medio. Es decir, cuando se haya determinado un Aprovechamiento Medio, y por tanto un Área de Reparto.

Por tanto, y a modo de resumen, las TAU de la LOUA únicamente pueden aplicarse (si lo determina el planeamiento) en la categoría de suelo urbano no consolidado siempre que se cuente con la delimitación de un Área de Reparto y no se encuentre en el ámbito de una unidad de ejecución. 
Si no existe delimitación de Área de Reparto, aun tratándose de suelo urbano no consolidado, lo único que se produce es el deber cesión del 10\% del aprovechamiento objetivo (es decir el que puede materializarse en la propia parcela), tal como dispone el art.58.2 párrafo segundo. Pero esta cesión del $10 \%$ del aprovechamiento objetivo no es una transferencia, porque no existe otra parcela con aprovechamiento nulo, sino que deriva de la misma parcela que lo genera, y por ello esta cesión se instrumenta mediante su compensación económica sustitutiva.

\section{LAS DIFERENTES SUBCATEGORÍAS DEL SUELO URBANO NO CONSOLIDADO}

Llegado a este punto, resulta necesario destacar una importante matización que incorpora la LOUA respecto al régimen del suelo urbano no consolidado, y que se pone de relieve cuando se aborda el análisis de la regulación de las TAU:

$1^{\circ}$. En la LOUA el régimen del suelo urbano no consolidado no es uniforme. De la regulación establecida en el art.55 se pone de manifiesto que existen tres subcategorías de suelo urbano no consolidado con una graduación del alcance de los deberes urbanísticos.

\section{2ํ. Las Subcategorías del Suelo Urbano No Consolidado son:}

1ª. Suelo Urbano No Consolidado incluido en ámbitos de delimitación de Unidad de Ejecución (necesariamente con delimitación de Área de Reparto).

2a . Suelo Urbano No Consolidado incluido en Área de Reparto y excluido de Unidad de Ejecución.

3 ${ }^{\text {a }}$. Suelo Urbano No Consolidado no incluido en Área de Reparto (y por tanto, sin posibilidad de delimitación de unidad de ejecución).

A cada subcategoría de suelo urbano no consolidado, la LOUA les anuda un régimen propio de derechos y deberes, que constituyen estatutos diferenciados del contenido de propiedad inmobiliaria. El estatuto completo de deberes únicamente se exige para los propietarios del suelo urbano no consolidado incluidos en unidades de ejecución. Pueden existir suelos urbanos no consolidados en los que no se exige el régimen completo de deberes de cesión. 
Ahora bien, no podemos identificar inexistencia de unidad de ejecución con inexistencia de Área de reparto. Si no existe unidad de ejecución puede ocurrir que exista o que no exista delimitación de área de reparto. Si existe unidad de ejecución siempre habrá delimitación de Área de reparto.

La regulación general del art.51 LOUA para el suelo urbano no consolidado se complementa con la establecida en el art.55. Este precepto diferencia tres supuestos dentro del urbano no consolidado.

\section{a) Cuando se establezca o se prevea la delimitación de unidades de eje- cución en el planeamiento:}

Si el planeamiento delimita unidades de ejecución o sin llegar a delimitarlas directamente prevé que así se proceda después bien por el planeamiento de desarrollo (suelo urbano con Plan Parcial o Especial) o por el procedimiento específico en fase de ejecución, el régimen del suelo urbano no consolidado es, según el art.55.1, es el mismo que el del suelo urbanizable ordenado o sectorizado, dependiendo de si tiene o no ordenación detallada (pormenorizada).

Las cesiones de terrenos para este tipo de suelo urbano no consolidado (el de unidades de ejecución) son las referenciadas en el art.54.2 (precepto que establece el régimen del suelo urbanizable ordenado). Por tanto, a nivel de cesiones el régimen del suelo urbano no consolidado incluido en unidad de ejecución es idéntico que el suelo urbanizable ordenado. En concreto estas cesiones de terrenos son:

1. La superficie total de los Sistemas Generales y demás dotacionales de carácter local incluidas en el ámbito de la unidad de ejecución.

2. La superficie de suelo con aprovechamiento lucrativo ya urbanizado para materializar el 10\% del aprovechamiento medio del área de reparto que le corresponda a la Administración Urbanística en concepto de participación de la comunidad en la recuperación de plusvalías generadas por la actividad pública de planificación.

3. La superficie de suelo correspondiente a los excedentes de aprovechamiento que tenga la unidad de ejecución respecto del aprovechamiento medio del área de reparto. Esta cesión de suelo no es urbanizada a diferencia de la anterior. Los excesos se podrán destinar a compensar a propietarios afectados por sistemas generales y restantes dotaciones, así como a propietarios de terrenos con un aprovechamiento objetivo inferior al susceptible de apropiación en el 
área de reparto, y podrán sustituirse por otros aprovechamientos de igual valor urbanístico, o por su equivalente económico.

\section{b) El régimen del suelo urbano no consolidado no incluido en unidades de ejecución con delimitación de área de reparto.}

El régimen urbanístico del suelo urbano no consolidado para el que la ordenación urbanística no prevea la delimitación de unidades de ejecución, es el siguiente:

a) Los propietarios están obligados a cumplimentar los deberes pendientes que corresponden al suelo urbano no consolidado. Ahora bien, así como las cesiones para usos públicos son las mismas prescritas para el suelo urbanizable, en cambio la de superficie de suelo ya urbanizada precisa para materializar el aprovechamiento lucrativo correspondiente a la participación del $\mathrm{Mu}$ nicipio será del diez por ciento del aprovechamiento medio del área de reparto correspondiente.

Si la urbanización no está completada, debe de satisfacerse este deber. La LOUA no especifica el modo en el que se procede a cumplimentar este deber cuando no existe unidad de ejecución y las obras afectan a más de un propietario (curiosamente sí se refiere a la posibilidad de delimitar una unidad de ejecución con esta exclusiva finalidad).

b) Los propietarios tienen derecho al noventa por ciento del aprovechamiento medio del área de reparto. Las cesiones del 10\% del aprovechamiento de la Administración, se producen mediante cesión material o compensación económica sustitutoria, y la cesión de los excesos respecto al Aprovechamiento Medio se realizan mediante transferencias de aprovechamientos urbanísticos.

La materialización del aprovechamiento mediante la edificación podrá autorizarse aún cuando la parcela correspondiente no tenga todavía la condición de solar, siempre que se cumplan los siguientes requisitos:

$\left.1^{\circ}\right)$ La cesión del suelo correspondiente al aprovechamiento urbanístico imputable al Municipio por razón de su participación en las plusvalías y la adquisición, en su caso, mediante transferencias de aprovechamiento, de los excedentes de aprovechamiento o sus equivalentes económicos.

$2^{\circ}$ ) Asunción expresa y formal por el propietario de los compromisos de proceder a la realización simultánea de la urbanización y la edificación y de 
formalización de las cesiones aún pendientes, así como de la no ocupación ni utilización de aquélla hasta la total terminación de las obras de urbanización, la materialización de las cesiones pendientes y el efectivo funcionamiento de los servicios correspondientes.

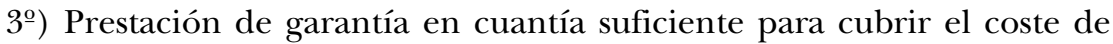
ejecución de las obras de urbanización comprometidas.

Por tanto, y a modo de conclusión, podemos decir que, en el suelo urbano no consolidado en el que no se delimite unidad de ejecución pero se encuentre adscrito a un Área de Reparto, las cesiones de terrenos son las mismas que para el caso de que se cuente con esa delimitación de unidad de ejecución. La diferencia entre estos dos supuestos radica en que la cesión de todos los terrenos calificados de uso público no se realiza de forma simultánea cuando no se delimita unidad de ejecución, sino que se produce de forma gradual, a través del juego de las Transferencias de Aprovechamientos Urbanísticos. De igual modo, la obligación de urbanizar de los terrenos incluidos en el Área de Reparto pero sin unidad de ejecución, tampoco tiene porqué realizarse necesariamente de modo integrada y simultánea en el tiempo.

En estos casos, el deber de ejecutar la urbanización está referido a las obras que afectan a la vía o vías que den frente la parcela, las correspondientes a todas las demás infraestructuras, nuevas o complementarias a las existentes, necesarias para la prestación de los servicios preceptivos, hasta el punto de enlace con las redes que estén en funcionamiento, así como el refuerzo de estas redes, si fuera preciso para la correcta utilización de los servicios públicos (art.55.2.B.b). No se alude a la ejecución de las obras de ajardinamiento y dotación de espacios libres, así como la urbanización de los espacios destinados a equipamientos. No obstante, por aplicación supletoria de las reglas de la reparcelación, y pudiéndose entender que son servicios preceptivos, puede reconocerse que pueden repercutirse como costes de urbanización. Tampoco explicita, si se pueden repercutir los costes de indemnización de las edificaciones pero nada imposibilita que puedan entenderse como costes necesarios para la ejecución de las obras de urbanización.

c) El régimen del suelo urbano no consolidado no incluido en unidades de ejecución y sin delimitación de área de reparto.

Si se trata de suelo urbano no consolidado no incluido en Unidad de Ejecución y además no adscrito a Área Reparto alguna, las cesiones de terrenos a favor de la Administración serán exclusivamente las correspondientes al $10 \%$ 
del aprovechamiento real atribuido sin que haya cesión de los excedentes de aprovechamientos, al carecer de determinación de Aprovechamiento Medio, y además, sin que se produzca cesiones para dotaciones (ni de Sistemas Generales ni locales).

Por tanto:

a) Los propietarios están obligados a cumplimentar los deberes pendientes que corresponden al suelo urbano no consolidado.

b) Pero no hay cesiones gratuitas para los terrenos calificados de usos públicos. Pese a lo que diga el art.55.2.A no es cierto que las cesiones de suelo son las mismas prescritas para el suelo urbanizable.

c) Sólo hay cesión de superficie de suelo ya urbanizada precisa para materializar el aprovechamiento lucrativo correspondiente a la participación del Municipio que será del diez por ciento del aprovechamiento objetivo que tuvieran asignado.

d) Los propietarios tienen derecho al noventa por ciento del aprovechamiento objetivo.

La materialización del aprovechamiento mediante la edificación podrá autorizarse aún cuando la parcela correspondiente no tenga todavía la condición de solar, siempre que se cumplan los siguientes requisitos:

$\left.1^{\circ}\right)$ La cesión del suelo correspondiente al aprovechamiento urbanístico imputable al Municipio por razón de su participación en las plusvalías o sus equivalentes económicos.

$2^{\underline{o}}$ ) Asunción expresa y formal por el propietario de los compromisos de proceder a la realización simultánea de la urbanización y la edificación así como de la no ocupación ni utilización de aquélla hasta la total terminación de las obras de urbanización, la materialización de las cesiones pendientes y el efectivo funcionamiento de los servicios correspondientes.

$3^{\circ}$ ) Prestación de garantía en cuantía suficiente para cubrir el coste de ejecución de las obras de urbanización comprometidas.

Así cuando en el suelo urbano no consolidado no exista Área de reparto, el $10 \%$ de recuperación de plusvalías se aplica sobre el aprovechamiento objetivo, y los propietarios de las parcelas con destinos a usos públicos no tendrán derecho a la distribución de beneficios y cargas, sino a una indemnización a cargo de la Administración, que al no poder ser compensada con excesos, no adquiere las dotaciones de forma gratuita sino de forma onerosa. 
Realmente cuando las parcelas del suelo urbano no consolidado excluidas de unidades de ejecución quedan también excluidas de Áreas de Reparto, es como si materialmente cada parcela funcionara en la práctica como un Área de Reparto independiente, de tal forma que el Aprovechamiento Medio coincide con su Aprovechamiento Objetivo (es decir el aprovechamiento lucrativo real), teniendo como obligación el propietario exclusivamente la de ceder el $10 \%$, sin que se produzcan excesos de aprovechamientos sobre el medio, y por tanto sin posibilidad de aplicar Transferencias de Aprovechamientos Urbanísticos para compensar a los propietarios de las parcelas que estando clasificadas como suelo urbano no consolidado se excluyan de unidades de ejecución y de Áreas de Reparto.

El deber de ejecutar la urbanización está igualmente limitado que en el estatuto de deberes anteriormente comentado ( a las obras que afectan a la vía o vías que den frente la parcela, las correspondientes a todas las demás infraestructuras, nuevas o complementarias a las existentes, necesarias para la prestación de los servicios preceptivos, hasta el punto de enlace con las redes que estén en funcionamiento, así como el refuerzo de estas redes, si fuera preciso para la correcta utilización de los servicios públicos).

\section{EXCLUSIÓN DE LAS TAU EN EL SUELO URBANO CONSOLI- DADO: INEXISTENCIA DE DEBERES DE CESIÓN EN ESTA CA- TEGORÍA DE SUELO}

Por el objeto y finalidades propias de las TAU, esta técnica no puede ser aplicada en el suelo urbano consolidado. Como se ha comprobado esta técnica tiene como finalidades hacer efectivo las obligaciones de cesión de suelo y del aprovechamiento urbanístico. La legislación urbanística considera que en el suelo urbano consolidado el proceso de transformación urbanística ha culminado, y si acaso, lo que resulta necesario es completar la urbanización existente para alcanzar la condición de solar.

Por ello, la LOUA siguiendo el régimen de condiciones básicas establecido por la Ley 6/1998 de Reforma del Suelo y Valoraciones no impone como deberes al propietario del suelo urbano consolidado ni el de cesión de suelo para usos públicos ni el de cesión del aprovechamiento.

Desde una interpretación que integre la regulación del art.56 con el art.51.1.D de la LOUA y que además sea compatible con la ley estatal, resulta que el propietario del suelo urbano consolidado tiene la facultad de materiali- 
zar, mediante la edificación, el aprovechamiento urbanístico correspondiente atribuido por el planeamiento, previo cumplimiento de los siguientes deberes:

a) Solicitar y obtener las autorizaciones administrativas preceptivas con carácter previo a cualquier acto de transformación o uso del suelo.

b) Realizar la edificación en las condiciones fijadas por la ordenación urbanística, una vez el suelo tenga la condición de solar, lo que precisa:

c) Completar la urbanización en ese supuesto en el que la parcela no mereciera la condición de solar.

Además, el propietario del suelo urbano una vez ha edificado tiene el deber de conservar, y en su caso rehabilitar, la edificación realizada para que mantenga las condiciones requeridas para el otorgamiento de autorización para su ocupación.

\section{Por tanto, los propietarios del suelo urbano consolidado no tienen deber alguno de ceder aprovechamientos ni suelos para usos públicos.}

La posibilidad de que el legislador autonómico pudiera estableciera el deber al propietario del suelo urbano consolidado de la cesión de aprovechamientos urbanísticos ha sido descartada expresamente por el Tribunal Constitucional en el marco de la actual regulación estatal (LRSV 1998) en su Sentencia 54/ 2002, de 27 de febrero que tenía como objeto la Ley del Parlamento Vasco 11/1998.

Esta sentencia recuerda que la STC 164/2001 ya manifestaba que desde la perspectiva del derecho a la igualdad «la inexistencia de deberes de cesión de suelo (en el urbano consolidado) no constituye discriminación alguna entre personas y por circunstancias subjetivas, que es lo prohibido por el art. 14 $\mathrm{CE}$, sino distintas regulaciones abstractas del derecho de propiedad urbano». Y que desde una perspectiva competencial, esta sentencia ya aclaraba que "para la participación de la comunidad en las plusvalías urbanísticas (mediante la regulación de las condiciones básicas de ejercicio del derecho de propiedad) el Estado dispone de un amplio margen de configuración»; y que «el art. 47 CE no impide, en este sentido, que la participación en las plusvalías se concentre en determinadas clases de suelo. De esta forma, la hipotética existencia de plusvalías urbanísticas en suelo urbano consolidado, cuya realidad no corresponde dilucidar a este Tribunal, no excluye a priori una norma estatal que alivie de cesiones de aprovechamiento a sus propietarios». 
En su fundamento quinto, la STC 54/2002 señala:

Quinto: Sentado lo anterior, basta con la lectura del artículo único, ap. 1, de la Ley del Parlamento Vasco 11/1998 para concluir que contradice las «condiciones básicas» contenidas en el art. 14 LRSV. En efecto, el art. 14.2 c) LRSV, (...) únicamente prevé deberes de cesión de aprovechamiento urbanístico en suelo urbano «no consolidado por la urbanización». En cambio, el art. 14.1 LRSV se limita a establecer, como deberes específicos de los propietarios de terrenos en suelo urbano "consolidado», el de completar a su costa la urbanización hasta que alcancen la condición de solar y el de edificarlos en los plazos establecidos por el planeamiento. Ello implica, como se razonó en el FJ 20 de la TC S 164/2001 que, conforme a dicha norma, los propietarios de suelo urbano «consolidado» no soportan (a diferencia de los propietarios de suelo urbano «no consolidado») deberes de cesión de aprovechamiento urbanístico, ni siquiera en solares o terrenos ya edificados pero sujetos a obras de rehabilitación. (...) Tenemos, así, que la norma de «condiciones básicas» del art. 14.1 LRSV, dentro del amplio margen de configuración de que dispone el Estado y en línea con las determinaciones expresas de sus antecedentes normativos, determina que todos los propietarios de suelo urbano «consolidado» de España patrimonializan el 100 por 100 del aprovechamiento urbanístico correspondiente a cada parcela o solar.

“... en la estructura normativa del art.14 LS98 las cesiones obligatorias de aprovechamientos no son un mínimo superable por cada Comunidad Autónoma sino, justamente, un máximo reducible en cada Comunidad; así resulta claramente del enunciado literal del art.14.2.c) LS98. En este sentido, la exclusión de toda cesión obligatoria de aprovechamiento urbanístico en el suelo urbano consolidado no admite modalización alguna de origen autonómico, Pues si la igualación de todos los propietarios de suelo urbano consolidado reside tanto en los deberes positivos a que se ha hecho referencia como en la inexistencia de deberes de cesión de aprovechamiento urbanístico -y sentado que aquélla es una opción válida, según razonamos en el FJ 4- la imposición de deberes de cesión de aprovechamiento urbanístico por las Comunidades Autónomas frustraría el fin igualador buscado por los arts.149.1.1 CE y 14.1 LS98..”.

La LOUA ha seguido esta doctrina del Tribunal Constitucional y reconoce la legitimación del propietario de una parcela del suelo urbano consolidado para patrimonializar la totalidad del aprovechamiento urbanístico atribuido por el planeamiento a la misma. 
Las posibilidades de construir unas TAU de aplicación voluntarias en suelo urbano consolidado (como se hizo por la práctica del urbanismo en el régimen del TRLS76) se ven dificultadas, no sólo por la anterior doctrina del Tribunal Constitucional, que reconoce que en el marco de la actual LRSV todo el aprovechamiento objetivo correspondiente a una parcela o solar en el suelo urbano consolidado corresponde al propietario, sino además por la propia LOUA.

En efecto, la posibilidad de intentar la construcción de una fundamentación similar a las que sirvieron de base al nacimiento de las TAU de principios de los ochenta (es decir, cesiones voluntarias no obligatorias, reparcelaciones voluntarias en el que se establecían dos determinaciones de planeamiento: una edificabilidad media y una máxima condicionada) resulta imposibilitada también por la propia LOUA, pues conforme a la misma, la base de partida de aquella construcción doctrinal de TAU anteriores al TRLS 1992, es decir los incrementos de aprovechamientos sobre la media, se conceptualizan en la ley andaluza como supuestos de suelos urbanos no consolidados y no como consolidados.

Por tanto, en suelo urbano consolidado no es posible aplicar Transferencias de Aprovechamientos ni siquiera con el carácter de voluntarias.

\section{ACTUACIONES URBANÍSTICAS SUSCEPTIBLES DE EJECUTAR- SE MEDIANTE TRANSFERENCIAS DE APROVECHAMIENTOS}

Son susceptibles de ejecutarse mediante Transferencias de Aprovechamientos, aquellas actuaciones urbanísticas del suelo urbano no consolidado en las que el Plan de forma justificada decida no delimitar unidades de ejecución, bien por imposibilidad o porque resulte desaconsejable por dificultar la gestión.

Son actuaciones urbanísticas que están presididas por una voluntad municipal de adquirir de forma gratuita las nuevas dotaciones públicas, además evidentemente de recuperar el $10 \%$ del aprovechamiento que como Administración Urbanística actuante le corresponde, y de poder repercutir (aunque sólo sea parcialmente) los costes de urbanización.

En principio, existen tres clases de actuaciones urbanísticas posibles en suelo urbano no consolidado, tal como se deduce de una interpretación conjunta de los art.45.2.B y 17 y 10 de la LOUA: 
a) sectores de suelo urbano no consolidado.

b) áreas de reforma interior.

c) áreas homogéneas de la edificación en las que se incrementa el aprovechamiento urbanístico.

\section{Los Sectores en el Suelo Urbano No Consolidado.}

Los Sectores son superficies relevantes de terrenos situadas en la periferia o en el interior de la ciudad, con pocas edificaciones, que son susceptibles de ser ordenados mediante Plan Parcial.

La LOUA parece que descarta la posibilidad de aplicar las TAU en los sectores del suelo urbano no consolidado. El art. 13.1.a) de la LOUA dispone que el Plan Parcial establece la ordenación detallada de sectores enteros en suelo urbano no consolidado (además de los sectores del urbanizable) para su ejecución integrada.

Por tanto, todos los sectores, incluidos los delimitados en el suelo urbano no consolidado, se ejecutan de forma integrada, es decir mediante unidades de ejecución, lo que excluye la aplicación de las TAU (que es una técnica de ejecución subsidiaria respecto a la delimitación de unidades de ejecución).

\section{Las Áreas de Reforma Interior.}

Las actuaciones integradas de reforma interior (supuesto regulado en el art.45.2.B.a.2) representan una segunda tipología de intervenciones planificadoras en concretas zonas del suelo urbano no consolidado.

Normalmente las áreas de reforma interior serán actuaciones en tejidos urbanos existentes que presentan signos de obsolescencia, sobre todo en suelo anteriormente clasificado como urbano en los que se propone una reforma de la ordenación anterior, y serán sectores las actuaciones sobre terrenos que anteriormente estaban clasificados como urbanizables o no urbanizable. No obstante, también, de forma excepcional, podrán conceptualizarse como áreas de reforma interior, ámbitos que con anterioridad no tengan la clasificación de urbano pero que cuentan con alto nivel de consolidación de la edificación y una urbanización primaria, aunque insuficiente, que precisa de mejoras así como prever un nivel mínimo de dotaciones y en los que difícilmente pueda plantearse su ordenación como sector precisamente por ese alto nivel de consolidación de la edificación. 
Existe una diversidad de intervenciones que pueden calificarse de actuaciones integradas de reforma interior: de una parte, cuando la urbanización existente, pese a que puede llegar a contar con todos los elementos infraestructurales, precisa de una renovación (operaciones de sustitución generalizada de las edificaciones y usos existentes para creación nuevos espacios urbanos), de una mejora (operaciones que alternan la sustitución de parte de los tejidos con conservación del resto de las edificaciones) o rehabilitación mediante actuaciones integradas dirigidas al establecimiento de la urbanización precisa y del nivel de dotaciones adecuados a las características de su población.

Pero no basta la simple obsolescencia sino que además su renovación, mejora o rehabilitación se realice mediante actuaciones integradas de reforma interior.

Las áreas de reforma suelen llevar también incrementos de aprovechamientos, y además este incremento suele ser considerable. Difícilmente puede plantearse una reforma interior si se mantienen los aprovechamientos urbanísticos, porque estas actuaciones (de renovación urbana) tienen que partir de unos costes de suelo y urbanización muy superiores a las actuaciones del suelo urbanizable. La diferencia con el supuesto del art.45.2.B.b) de la LOUA, será una cuestión no sólo de la intensidad en la transformación urbana propuesta sino su carácter de integral

Ahora bien, el concepto de actuación integrada no debe asimilarse necesariamente con el de actuación sistemática, esto es, que se incluyan en una unidad de ejecución, pero sí que se incorporen en una ordenación específica e integrada de un ámbito territorial determinado, en definitiva que respondan a una planificación integral.

Las áreas de reforma interior pueden, por tanto, ejecutarse mediante unidades de ejecución o de forma asistemática mediante transferencias de aprovechamientos, sin descartar una solución mixta.

Al tener carácter preferente la delimitación de unidades de ejecución, ésta será la primera opción en la elección de la técnica de ejecución de las áreas de reforma interior. Pero no puede descartarse que para determinadas zonas del área de reforma interior se opte por la aplicación de las TAU, especialmente cuando la delimitación de las unidades presente grandes dificultades de gestión por el nivel de consolidación existente.

La posibilidad de delimitación de unidades de ejecución discontinuas presenta una nueva variable, que exigirá justificar incluso la imposibilidad de 
la delimitación de una unidad de ejecución de esta clase para poder aplicar las TAU. En estos casos, lo principal será la imposibilidad de su gestión conjunta, por el número de parcelas ya edificadas, cuya renovación forzada puede dificultar la constitución de Juntas de Compensación.

De ahí que se suela optar por esta técnica de gestión "diferida" que representan las TAU, únicamente cuando el hacerlo en el seno de Unidades de Ejecución sea significativamente más complejo.

Es la actuación asistemática, en cierto modo, una forma de gestión "residual" que se aplica a situaciones urbanas especialmente conflictivas: una microparcelación combinada con una situación de consolidación edificatoria sobre la que el Plan pretenda básicamente su reconocimiento, mejorando aunque sea mínimamente los índices dotacionales y los servicios de infraestructuras. Las TAU en estos casos, tendrán como finalidad principal obtener gratuitamente los suelos de uso público (nuevos viarios, ampliación de los existentes, suelo para espacios libres y equipamientos) ubicándolos generalmente en algunas parcelas vacantes de edificación (para reducir los costes de adquisición). La adquisición de estos terrenos se realizará directamente por la Administración mediante expropiación o bien mediante acuerdos de transferencias entre los particulares. En cualquier caso, si la Administración expropia, recuperará el coste en el proceso de ajuste de aprovechamientos que debe producirse de las parcelas edificables. Al final del proceso esa adquisición de terrenos de usos públicos se realiza de modo gratuito para el Municipios pues se repercute en las parcelas edificables.

Por tanto, en las áreas de reforma interior se plantea la aplicación de las TAU en ámbitos en los que la presencia de la edificación es importante, y en el que la estructura de la propiedad se encuentra fragmentada, y resulta desaconsejable la delimitación de unidades de ejecución, en su doble modalidad, sea continua o discontinua.

3. Las Áreas Homogéneas de Edificación en las que se incrementa el aprovechamiento.

Las Áreas Homogéneos de Edificación con incremento de aprovechamiento, también son actuaciones urbanísticas susceptibles de incorporar la técnica de las TAU.

Ahora bien, no en todas las áreas homogéneas de la edificación en las que se incrementen los aprovechamientos pueden aplicarse las TAU, sino sólo en 
las que se haya delimitado un Área de Reparto: Serían aquellas áreas en las que, a parte de incrementarse el aprovechamiento y mejorar la urbanización, se procede a incrementar el nivel de los espacios y dotaciones públicas. Pues si sólo se requiere el incremento o mejora los servicios públicos y de urbanización existentes, no será necesario delimitar área de reparto, y por tanto, aplicar las TAU, salvo que la asignación del incremento del aprovechamiento no sea idéntica para todas las parcelas.

Hay que recordar que por regla general, y por aplicación del art.36.2.a. $2^{\underline{a}}$ de la LOUA, toda innovación del planeamiento que proponga un incremento de aprovechamiento urbanístico lucrativo requiere la previsión de nuevos espacios libres y dotaciones públicas como medida compensatoria para mantener la proporción y calidad de las dotaciones.

Por ello, en la mayoría de los casos, los incrementos de aprovechamientos en las Áreas Homogéneas de Edificación exigirán una previsión de mayores espacios libres y dotaciones en proporción a las necesidades derivadas del incremento de población que genera ese incremento considerable del aprovechamiento. En estos casos, lo lógico será que se establezca como mecanismo para su obtención gratuita la aplicación de TAU, delimitándose un Área de Reparto, que permita la obtención gratuita de las nuevas dotaciones requeridas.

Sólo en aquellos casos en los que el incremento de aprovechamiento aun siendo considerable no supone en realidad un incremento del número de viviendas, y por tanto de la población, no será necesario incrementar las dotaciones públicas (aunque sí los servicios de infraestructuras para adaptarlos a los nuevos requerimientos), por ello, en estos casos, será un supuesto de suelo urbano no consolidado sin área de reparto, y por ello, sin posibilidad de aplicar TAU. Un ejemplo, sería cuando en una zona de ordenanzas, la revisión del planeamiento urbanístico permite un incremento de aprovechamiento urbanístico (de las condiciones de la edificación: generalmente la ocupación) sin incrementar el número de viviendas, y evidentemente sin ninguna alteración en el tejido urbano (tanto desde el punto de vista de su transformación como de cambio de usos).

Las áreas de incremento de aprovechamientos en las que se puede aplicar las TAU se diferencia de las áreas de reforma interior no sólo en la intensidad de la transformación de la estructura urbana (mucho menor) sino también, en el carácter no integral de la propuesta de renovación.

La recualificación en algunas zonas puede realizase mediante la atribución de un incremento del aprovechamiento objetivo, acompañada de pe- 
queñas mejoras infraestructuras, sin alteraciones sustanciales en el tejido urbano, salvo para la mejora puntual de accesos y obtención algunos espacios -pequeños- para equipamientos (generalmente de zonas verdes).

Las TAU se aplican a estos supuestos con alto grado de fraccionamiento de la estructura de la propiedad (microparcelación) y de nivel consolidación de la edificación, en los que no se pretende una renovación de la edificación forzada, sino incentivadora por esas mayores posibilidades que ofrece el plan en la materialización de aprovechamientos, permitiendo en una gestión diferida la obtención gratuita de los suelos de cesión y la recuperación de las plusvalías.

\section{LA EJECUCIÓN URBANÍSTICA POR TRANSFERENCIAS DE APROVECHAMIENTOS URBANISTICOS}

\subsection{Funciones y Naturaleza jurídica de las Transferencias}

Para realizar una aproximación a la figura de las TAU, debemos clarificar cuál es su naturaleza jurídica. Esta debe quedar determinada en atención a las funciones que cumple.

Para ello partimos del apartado 1 del art.62 LOUA en la que se describe su resultado material:

“... La transferencia determina la justa distribución del aprovechamiento objetivo entre los propietarios intervinientes y legitima su materialización por éstos".

De este primer párrafo, podemos deducir que la TAU tiene como finalidad la justa distribución del aprovechamiento objetivo atribuido por un planeamiento previamente aprobado, legitimando su materialización por los interesados (ahora bien, no es verdad que legitime siempre su materialización por los intervinientes, lo ordinario será que sólo legitime a uno de ellos para materializar el aprovechamiento objetivo, el otro interviniente será compensado económicamente).

Se trata, en definitiva, de una técnica de ejecución del planeamiento, y por ello debería haberse encuadrado desde el punto de vista sistemático en el Título IV de la LOUA, y no en el Título II como se hace.

Las TAU es una técnica de ejecución urbanística que tiene por finalidad procurar el ajuste entre necesario entre el aprovechamiento subjetivo y el objetivo para legitimar la materialización de éste. 
Todos los propietarios de parcelas de un área de reparto tienen igual aprovechamiento subjetivo. El derecho a un aprovechamiento patrimonializable es idéntico para todos los propietarios del área de reparto: el $90 \%$ de su Aprovechamiento Medio y es independiente de que el terreno que origine ese derecho pueda edificarse o esté destinado a usos públicos. Pero los aprovechamientos objetivos (los reales, los que realmente pueden edificarse) se sitúan de forma dispar en las parcelas conforme a las decisiones de planeamiento. Todo propietario de un aprovechamiento subjetivo tiene derecho a materializarlo en una parcela edificable o a recibir una compensación económica sustitutiva.

Por tanto, cuando se aprueba el planeamiento se produce una situación inicial de desajuste y desencuentro de los aprovechamientos urbanísticos reales respecto a los patrimonializables, de forma que el aprovechamiento subjetivo no suele coincidir con el aprovechamiento real de las parcelas. Por ello, se hace necesario realizar un ajuste entre uno y otro a fin de garantizar el principio de equidistribución y permitir la materialización de las previsiones del plan.

El derecho al aprovechamiento urbanístico aunque es un derecho desvinculado del suelo, tiene como finalidad última su materialización en edificación en aquellas parcelas con los aprovechamientos urbanísticos reales adecuados. La ejecución urbanística del planeamiento persigue precisamente que las parcelas en las que se puede edificar cuenten efectivamente con todos los aprovechamientos objetivos patrimonializados por aquellos que están legitimados para solicitar la licencia previa a la edificación. De no tenerlos, se ponen técnicas para lograrlo.

La facultad de promover la transformación urbanística no es sino una manifestación del derecho al aprovechamiento, a su titular se le atribuyen facultades para poder transformar ese derecho al aprovechamiento en edificación mediante el cumplimiento de una serie de deberes. Por tanto, todas las acciones de los titulares y de la Administración irán dirigidas a producir ese ajuste o encuentro entre los aprovechamientos subjetivos y los objetivos para que el derecho al aprovechamiento urbanístico se pueda transformar en el derecho a la edificación.

La Transferencia es un modo para llevar a cabo a esos ajustes o encuentros en la medida que permite el traslado de los aprovechamientos subjetivos hacia las parcelas con aprovechamientos reales excedentarios.

Es una técnica de ejecución urbanística que pretende aplicar criterios de distribución de beneficios y cargas en el suelo urbano no consolidado en ac- 
tuaciones urbanísticas en las que no se haya procedido a la delimitación de unidades de ejecución.

Por tanto, se trata de una técnica de ejecución urbanística asistemática. La ejecución asistemática puede darse en el suelo urbano consolidado o en el no consolidado. En el suelo urbano no consolidado la actuación asistemática es subsidiaria, y sólo puede establecerse cuando no sea posible o conveniente delimitar una unidad de ejecución.

Con la TAU no se produce una ejecución simultánea del planeamiento, sino de forma progresiva y desfasada en el tiempo. En el seno del área de reparto se realizarán las diversas transferencias de aprovechamientos como actos parciales y sucesivos de ejecución de las previsiones del Plan.

Es una técnica dirigida principalmente a la adquisición gratuita de los suelos con destino a dotaciones públicas a cargo de las parcelas que tengan un aprovechamiento objetivo superior a la media.

Por ello, cumple la finalidad de hacer efectivo tres deberes de los propietarios del suelo urbano no consolidado:

a) el deber de cesión de terrenos calificados con usos públicos.

b) el deber de compensar a la Administración en concepto de recuperación de plusvalías, bien con parte de la parcela con excesos de aprovechamientos, bien en metálico (salvo supuestos de grandes parcelas, difícilmente el aprovechamiento municipal podrá materializarse en parcelas cedidas).

c) el deber de distribución de beneficios y cargas, pero sólo parcialmente, los correspondientes a los excedentes de aprovechamientos (el deber de distribuir los costes de urbanización no queda suficientemente garantizado, sino es con medidas complementarias establecidas por la Administración Urbanística Actuante).

Tiene naturaleza reparcelatoria, aun cuando no se regule en la sección séptima del capítulo I del Título IV. En realidad es una reparcelación (aunque especial) porque va dirigida a cumplir algunas de las finalidades establecidas en el art.100.2 de la LOUA, en concreto: la justa distribución de los beneficios y las cargas derivadas de la ordenación urbanística y de su ejecución (apdo b), la localización del aprovechamiento urbanístico en suelo apto para la edificación conforme al instrumento de planeamiento de que se trate (apdo c), y la 
adjudicación al municipio de los terrenos de cesión obligatoria y gratuita y, en su caso, de fincas resultantes constitutivas de parcelas o solares (apdo d).

Cuando se actúa por unidades de ejecución, el necesario ajuste entre los aprovechamientos reales atribuidos a los terrenos y los patrimonializables por sus titulares, se produce en un solo acto para todos los terrenos de la unidad mediante el proyecto de reparcelación contemplado para los sistemas de actuación, y que permiten una redistribución material de las propiedades afectadas sin perjuicio de las compensaciones económicas que procedan por diferencias de adjudicación.

Esta misma función cumplen las transferencias allí donde no se puede ejecutar el Plan por unidades de ejecución, si bien, de forma puntual y faseada en el tiempo. Y en el que las compensaciones económicas sustitutorias del deber de entrega de parcelas edificables tienen un protagonismo mayor ante las dificultades de distribución material. Pero las compensaciones económicas sustitutorias tampoco son ajenas a la reparcelación ordinaria que puede llevarse a cabo en especie o mediante indemnización sustitutoria de adjudicación de suelo (art.100.5 LOUA).

Es una reparcelación especial porque tiene un procedimiento específico y el ámbito concreto de las fincas reparcelables que integran una concreta TAU se determina en el preciso instante en que se formula la propuesta de TAU.

En efecto, la especialidad de las TAU, es que en el seno del Área de Reparto no están predeterminadas ab initio las parcelas objeto de ajustes de aprovechamientos, existiendo múltiples variables de emparejamientos viables, basta que se encuentren en situación inversa con la cuantía necesaria. Ahora bien, una vez producido el emparejamiento, se produce una unión hasta el final.

De hecho, el ámbito concreto de las parcelas objeto de la transferencia puede decirse que constituye una unidad de ejecución discontinua para consumar la compensación de los aprovechamientos y la cesión de terrenos.

\subsection{Concepto}

La Transferencia de Aprovechamiento Urbanístico en la LOUA es una técnica de ejecución asistemática del suelo urbano no consolidado con delimitación de Área de Reparto por la que se procede al traslado del aprovechamiento subjetivo no materializable sobre una parcela (por tener un aprove- 
chamiento objetivo nulo -en el caso de estar destinada a uso público- o tener un aprovechamiento objetivo inferior al patrimonializable) a otra parcela en situación inversa, es decir en el que el aprovechamiento objetivo (el real materializable) es superior al aprovechamiento subjetivo (patrimonializable) de su titular.

El apartado 1 del art.62 de la LOUA describe en qué consiste las TAU y sus efectos:

“... los propietarios de una parcela o solar pueden transferir el aprovechamiento subjetivo que les corresponda y no puedan materializar en una $\mathrm{u}$ otro, a otras parcelas o solares en situación inversa, es decir, que tengan atribuido un aprovechamiento objetivo superior al que corresponda a sus propietarios. La transferencia determina la justa distribución del aprovechamiento objetivo entre los propietarios intervinientes y legitima su materialización por éstos".

Lo que se transfiere es el aprovechamiento subjetivo de imposible materialización en la parcela que lo origina ("los propietarios ... pueden transferir el aprovechamiento subjetivo..."). Y se transfiere a la parcela con excesos de aprovechamientos objetivos por encima del aprovechamiento subjetivo de su titular.

No es objeto de transferencia el aprovechamiento objetivo, que permanece siempre vinculado a la parcela según la calificación del planeamiento. La transferencia del aprovechamiento objetivo de una parcela a otra, no puede realizarse salvo modificación del plan, y el medio para llevarlo a cabo no es la TAU sino el expediente de aprobación de la alteración del instrumento de ordenación.

Para que pueda producirse la Transferencia, se tiene que dar la situación de desajuste: una parcela con aprovechamientos subjetivos que no puedan materializarse en ella por ser superiores a los reales y una parcela con aprovechamientos reales superiores a los subjetivos. El ajuste se consigue con el traslado de los aprovechamientos subjetivos hacia la parcela con aprovechamientos objetivos superiores a los patrimonializables para que aquéllos puedan ser materializados legítimamente.

3.3 Situaciones de las parcelas con respecto al aprovechamiento medio y posibilidades de transferencias.

En relación con el aprovechamiento subjetivo atribuido por el planeamiento, la situación de las parcelas y el aprovechamiento objetivo asignado a 
ellas, se plantea de forma diversa. Las situaciones de desajuste entre aprovechamiento subjetivo y objetivo se producen en tres casos, pero en sólo dos de ellas pueden plantearse las TAU:

- Situación 1a․ Parcela con aprovechamiento objetivo nulo y Parcela receptora con aprovechamiento objetivo igual o superior al aprovechamiento medio.

Es un supuesto en el que se puede aplicar las transferencias de los aprovechamientos subjetivos no materializables en la parcela (A) con aprovechamientos objetivos nulos (que por definición debe estar calificada con usos con destino públicos), que será la parcela transmitente a la parcela (B) con aprovechamientos objetivos superiores al aprovechamiento medio, que será la parcela receptora. En estos casos, para la validez de las transferencias se requiere la cesión gratuita de la parcela (A) calificada para usos públicos al Ayuntamiento.

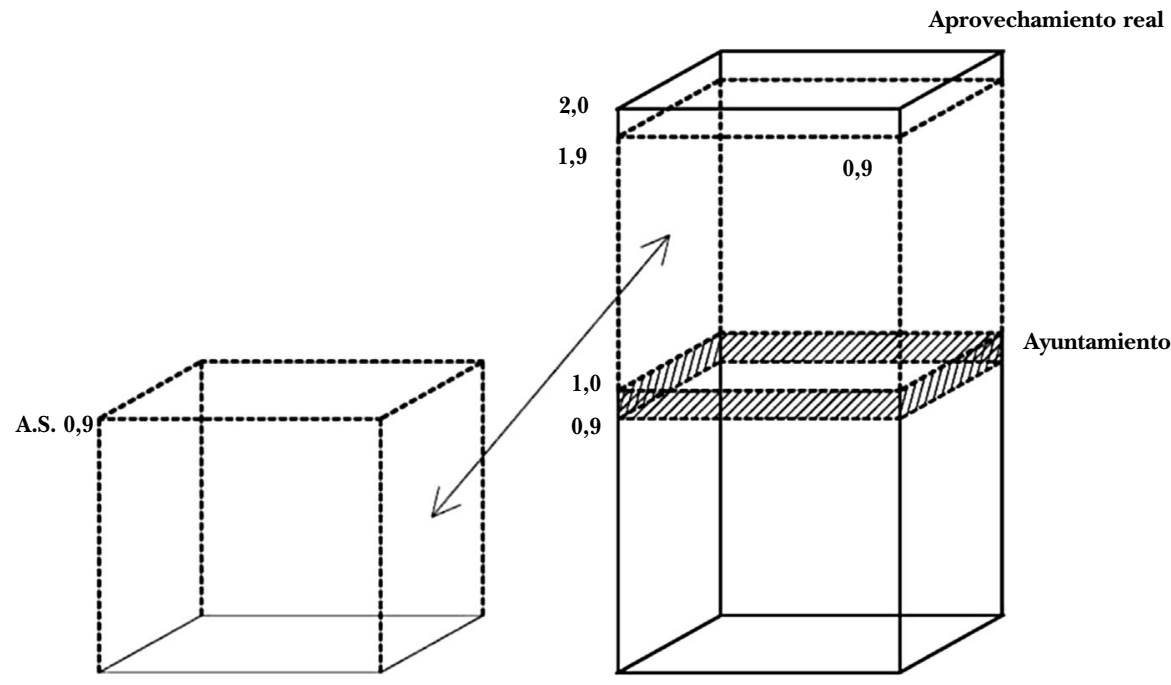

ESPACIO LIBRE PÚBLICO

Parcela A

Parcela B

APROVECHAMIENTO OBJETIVO: 0

APROVECHAMIENTO SUBJETIVO: 90\% APROVECHAMIENTO M. AR. 
- Situación 2ª . Parcela con aprovechamiento objetivo inferior al subjetivo y Parcela receptora con aprovechamiento objetivo superior al aprovechamiento medio.

Se trata de una parcela (A) con aprovechamientos lucrativos pero inferiores al aprovechamiento subjetivo. El aprovechamiento subjetivo de imposible materialización en la parcela (A) puede ser objeto de transferencia a otra parcela (B) con unos aprovechamientos objetivos superiores al resultado de aplicar a su superficie el aprovechamiento medio En este caso, se trata de una parcela (A) apta para la edificación si bien en cuantía inferior al aprovechamiento subjetivo de su titular, quien podrá edificar hasta esa cuantía y transferir el resto a una parcela (B) en situación inversa.

En este caso no se produce la cesión al Ayuntamiento de la parcela (A) que origina el aprovechamiento subjetivo que se transfiere.

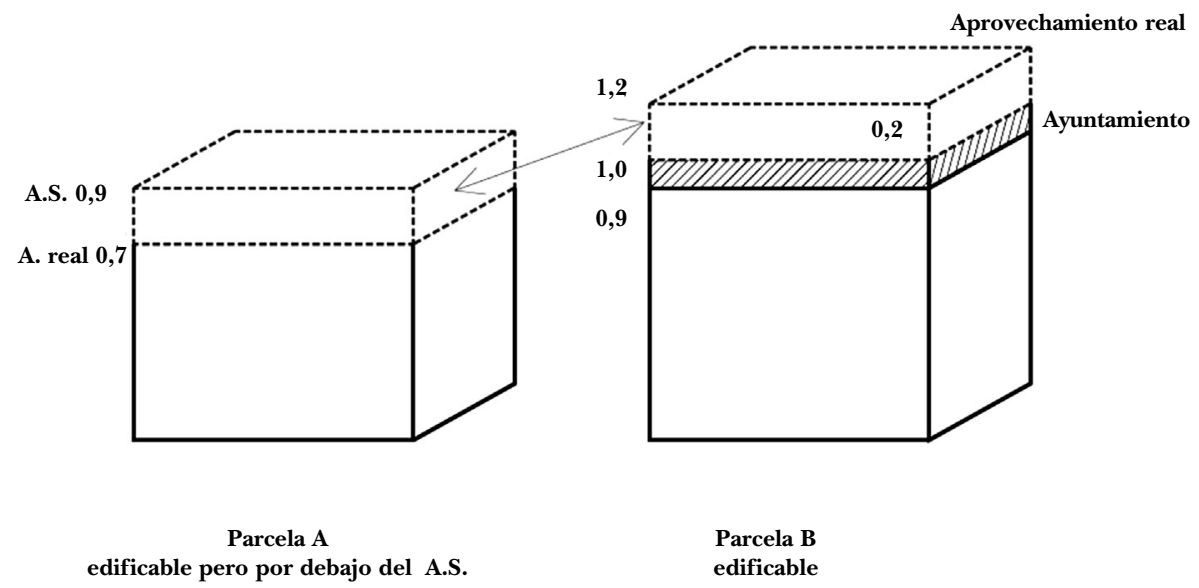


- Situación 3 $3^{\text {a }}$. Parcela con aprovechamiento objetivo superior al 90\% del Aprovechamiento medio pero igual o inferior al $100 \%$ aprovechamiento medio.

Se trata de una parcela edificable con aprovechamientos objetivos superiores al subjetivo pero en una cuantía no superior al 10\% del Aprovechamiento Medio. En este caso, no se produce una transferencia de aprovechamientos propiamente dicha, porque ese exceso pertenece a la Administración. El desajuste se resuelve en el seno de la misma parcela (A), mediante la cesión de la parte del aprovechamiento que le corresponda a la Administración Urbanística, mediante compensación económica sustitutiva (art.55.2.B.a y art. 64.1)

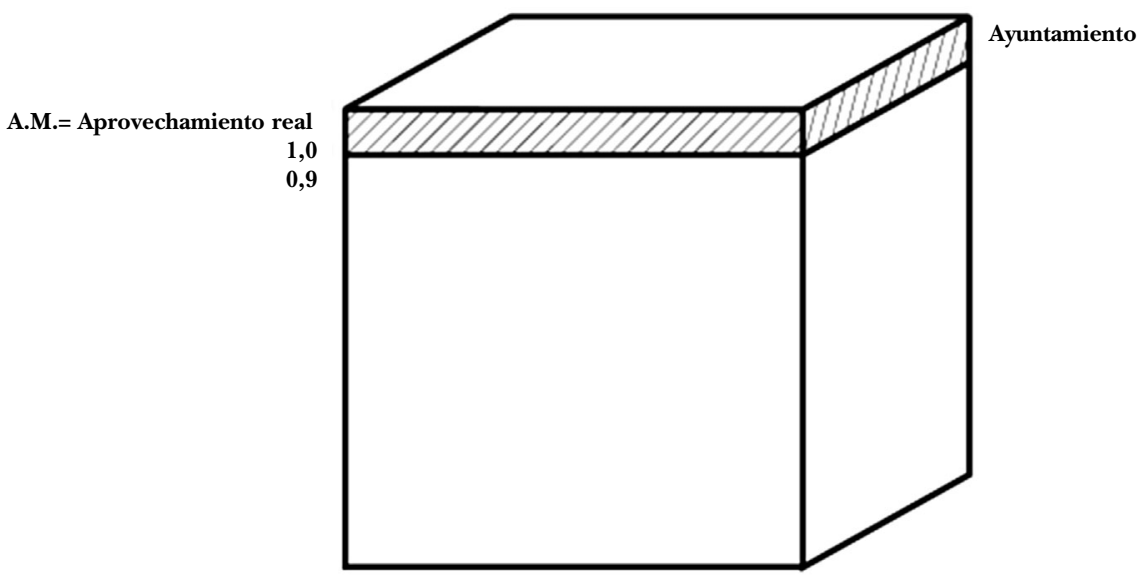

Parcela A

única 
- Situación 4⿳亠丷厂 . Parcela con aprovechamiento objetivo coincidente con el aprovechamiento subjetivo ( $90 \%$ aprovechamiento medio).

Se produce una situación de partida en el que el aprovechamiento objetivo de una parcela es idéntico al aprovechamiento subjetivo que le corresponde a su titular. Al existir esa coincidencia, el ajuste es perfecto, y no procede ni la cesión del aprovechamiento al Ayuntamiento ni la adquisición de excesos por transferencias.

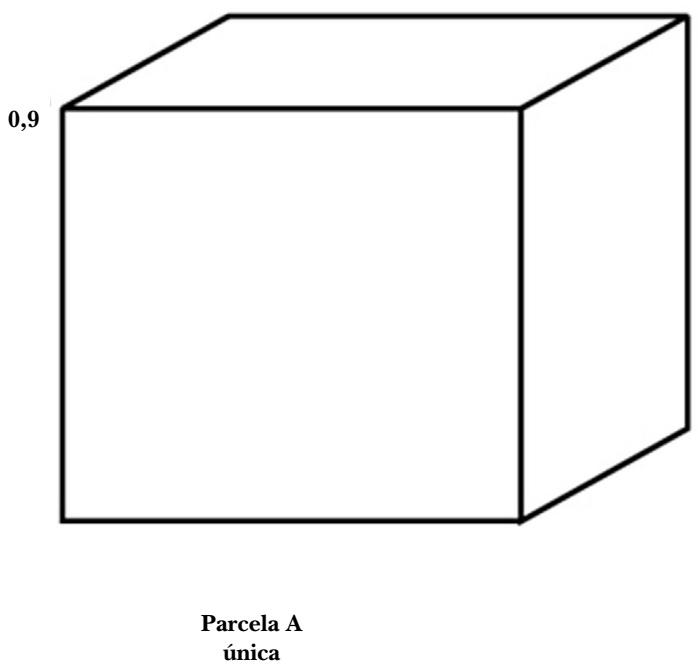




\subsection{Requisitos de eficacia de la transferencia}

El apartado 3 del art.62 LOUA establece un doble requisito de eficacia para la transferencia de aprovechamientos:

"la eficacia de toda transferencia requiere la cesión gratuita al Municipio, libre de cargas y en pleno dominio, de las superficies de suelo de que traiga su causa el aprovechamiento subjetivo que sea objeto de transferencia y la equivalencia, en términos de valor urbanístico, entre dicho aprovechamiento subjetivo y el aprovechamiento objetivo que sea atribuido por razón de éste"

En cuanto al primer requisito de eficacia (esto es la cesión gratuita de la parcela de la que traiga su causa el aprovechamiento subjetivo que es objeto de transferencia) representa una mala redacción de la LOUA. No puede establecer como requisito de eficacia para todas las transferencias la cesión gratuita de las superficies de suelo de que traiga causa el aprovechamiento subjetivo que sea objeto de transferencia.

La interpretación correcta es que esa cesión sólo se dará en el caso de que la parcela (A) de la que trae su causa el aprovechamiento subjetivo que se transfiere esté destinada a usos públicos (Situación Primera analizada, es decir, que tiene un aprovechamiento lucrativo nulo). Pero si el objeto de la transferencia es un aprovechamiento subjetivo que un propietario no puede materializar enteramente en su parcela, que cuenta con aprovechamientos objetivos, pero que son inferiores a su derecho de aprovechamiento (Situación Segunda), esa parcela no se cede, sino que sigue perteneciendo a ese propietario, que podrá materializar una parte de su aprovechamiento en su parcela y compensarse del déficit mediante la transferencia de ese aprovechamiento subjetivo no materializable a la parcela con excesos de aprovechamiento real, mediante acuerdo de cesión o distribución del aprovechamiento.

La hipótesis más corriente de transferencia se producirá entre una parcela que carece de aprovechamientos objetivos (aprovechamiento lucrativo nulo por estar destinada a usos públicos) con una parcela con excesos de aprovechamientos por encima del medio. Pero aunque éste sea el supuesto más normal de transferencias, no se trata más que una de las tipologías posibles de TAU. Por ello, habrá que entender que esa cesión de la parcela de la que traiga su causa el aprovechamiento subjetivo transferible, como requisito de eficacia que establece la LOUA, lo será en su caso, es decir si en el proceso de transferencias se pone en juego una parcela con usos públicos. 
En resumen, si los aprovechamientos subjetivos que se transmiten están originados en una parcela con aprovechamientos objetivos (en la que se puede edificar pero cuenta con aprovechamientos reales inferiores al aprovechamiento subjetivo de su titular, que tiene un remanente), la transmisión de esos aprovechamientos no lleva aparejado la transmisión de la parcela. Si los aprovechamientos subjetivos que se transmiten están originados en una parcela con aprovechamiento lucrativo nulo, entonces procede la cesión de esa parcela al Ayuntamiento.

El segundo requisito que establece el apartado 3 del art.62 LOUA es la equivalencia, en términos de valor económico, entre el aprovechamiento subjetivo objeto de transferencia y los aprovechamientos reales a los que se atribuye.

La ecuación que debe darse es la siguiente: valor del aprovechamiento subjetivo transferible $=$ valor del aprovechamiento objetivo excedentario que queda legitimado para su edificación.

Por tanto, se realizan dos valoraciones en función de su localización:

- Los aprovechamientos subjetivos que se transfieren se valoran conforme a la localización de las finca transmitente

- Los aprovechamientos reales se valoran conforme al valor de la finca receptora.

Como consecuencia, de la incidencia de la distinta valoración de unos aprovechamientos y otros, la paridad final o ajuste global de los aprovechamientos no queda garantizado por la aplicación de las TAU.

No puede entenderse el requisito de la equivalencia como correspondencia exacta de complementariedad perfecta de aprovechamientos (o mejor dicho de valoración de aprovechamientos) entre una finca y otra. Entre otras razones porque se establecería un sistema rígido de transferencias que exigiría que en cada operación se buscase una equivalencia exacta de valores urbanísticos de los aprovechamientos entre dos parcelas en situación inversa. Por el contrario, no puede descartase que una finca con aprovechamientos subjetivos que no pueden materializarse, puede ser objeto de sucesivas transferencias hasta agotar ese derecho.

La Administración no puede ser ajena a la valoración que realicen los particulares de las unidades de aprovechamientos, porque en otro caso se producirían graves desajustes. 


\subsection{Los Efectos de la Transferencia}

De lo expuestos en los epígrafes anteriores, puede concluirse que los efectos jurídicos de las Transferencias de Aprovechamientos Urbanísticos son:

1. La justa distribución de los beneficios y de las cargas de cesión de suelo gratuito a la Administración

2. la legitimación para materializar la edificación, si además se cumple el resto de requisitos.

3. En su caso, la cesión de la parcela con usos públicos.

\subsection{Modos de realizar la transferencia entre particulares. Tipos de acuerdos de transferencias}

La forma concreta como se realiza la transferencia entre particulares puede ser una cesión o una distribución (conforme al art.65.1.a).

A) Acuerdo de Cesión del aprovechamiento.- tiene como efecto la concentración en un mismo titular de la totalidad de los aprovechamientos subjetivos necesarios para poder materializar el $90 \%$ de los aprovechamientos objetivos que posibilita el plan sobre la parcela receptora. Mediante este acuerdo se consigue que el $90 \%$ de los aprovechamientos objetivos puede materializarse por un sólo propietario, que se encuentra legitimado de una parte, por ser titular de aprovechamientos subjetivos en la propia parcela receptora, y de otra, en virtud del acuerdo de cesión con el propietario de la parcela transmisora que le permite adquirir los aprovechamientos excedentarios. Por tanto, no sólo se transfieren de una parcela a otra los aprovechamientos subjetivos, sino que el propietario de la parcela transmisora los cede y los transmite, al titular de la parcela con aprovechamientos objetivos excedentarios, que los adquiere. Esta cesión se realiza mediante compensación económica sustitutiva (económica, sin perjuicio de otra forma de pago admitida por las partes). Para poder materializar el $100 \%$ de los aprovechamientos reales precisaría además llegar a un acuerdo con el Ayuntamiento de cesión del 10\% de los aprovechamientos reales que le corresponden a éste por ser Administración Urbanística actuante. Por tanto, el acuerdo de cesión es un acuerdo de venta.

El propietario de la Parcela A llega a un acuerdo con el propietario de la Parcela B (con aprovechamiento real deficitario con respecto a su aprovechamiento subjetivo) en virtud del cual, le transmite la totalidad de sus aprovechamientos subjetivos que no puede materializar, a fin de que el titular de la Parcela A quede legitimado para edificar mayores aprovechamientos reales. El 
propietario B recibe una compensación, quedando su Parcela con menor valor económico como consecuencia de la transmisión de los aprovechamientos subjetivos.

Aun cuando exista intervención administrativa, el acuerdo de cesión es un verdadero contrato de compraventa de aprovechamientos urbanísticos realizados entre privados, mediante el cual se transmiten esos aprovechamientos, que pasan de un patrimonio a otro, del titular de la parcela transmitente al titular de la receptora, quien los adquiere, quedando legitimado para acceder a su materialización.

B) Acuerdo de distribución de aprovechamientos.- este acuerdo de distribución es una verdadera reparcelación material, en el que en virtud de la transferencia de aprovechamientos que se produce desde la parcela transmitente (con aprovechamientos lucrativo deficitario) a la receptora (con aprovechamiento real superior al patrimonializable por su titular), los propietarios de ambas parcelas se reparten el $90 \%$ del aprovechamiento real de la parcela receptora conforme a su derecho de aprovechamiento. De esta forma, el propietario de la parcela con aprovechamientos reales deficitarios tiene derecho a la adjudicación de aprovechamientos reales en la parcela receptora. Hasta la materialización final de los aprovechamientos, ambos comporten el derecho a la edificación en proporción a sus derechos de aprovechamiento.

El acuerdo de distribución de aprovechamiento es el supuesto más preciso de transferencia de aprovechamiento en sentido estricto, atendiendo a su naturaleza reparcelatoria.

Siguiendo a Ma Jesús Jiménez Linares (en "El derecho al aprovechamiento urbanístico) puede decirse que la distribución implica un reparto de los aprovechamientos objetivos, en el que cada uno de los propietarios de las parcelas objeto de transferencias que se encuentran en situación inversa (es decir el titular del aprovechamiento subjetivo que debe trasladarse y el titular de la parcela con aprovechamientos reales excedentarios) se ponen de acuerdo en la adjudicación final de los aprovechamientos materializables. Un propietario aporta el terreno en el que se pueden materializar aprovechamientos urbanísticos que exceden de su derecho, y el otro aporta aprovechamientos subjetivos.

La Ley no reconoce un derecho del propietario de la parcela con aprovechamientos subjetivos a materializarlo en la parcela con excesos de aprovechamientos reales, sino que simplemente pone las condiciones para que estén abocados a entenderse. Los acuerdos pueden ser múltiples: cesión de parcela 
(si es segregable, en cuyo caso el resultado final es que un propietario cede el terreno o parte del mismo al propietario que cuente aprovechamiento subjetivo que no pueda materializar) o titularidad conjunta de la parcela si no es segregable, o incluso acuerdos más complejos, como puede ser el de promoción conjunta.

En todo caso, el acuerdo de transferencia entre los particulares no puede incidir en los intereses de la Administración y por ello ha de dejar margen para hacer efectivo el derecho al aprovechamiento urbanístico correspondiente al Ayuntamiento. Lo que significa que no se transfieren los aprovechamientos urbanísticos por cuantía equivalente a los aprovechamientos que faltan por patrimonializar, sino que la parte correspondiente al $10 \%$ del aprovechamiento medio en cada parcela perteneciente a la Administración no puede ser transferida en los acuerdos entre los particulares, por que ese aprovechamiento municipal se encuentra vinculado a la finca con excesos de aprovechamientos reales.

\subsection{Los acuerdos entre particulares y el Ayuntamiento de transmisión de apro- vechamientos}

El art.64.1 de la LOUA dispone que con ocasión de la solicitud de licencia, los municipios podrán transmitir directamente y por precio a satisfacer en metálico, la totalidad o parte del aprovechamiento objetivo atribuido a una parcela que exceda del aprovechamiento subjetivo correspondiente a su propietario.

Aun en las TAU celebradas entre particulares, bien en el propio acuerdo o en el momento de su aprobación, se pone de relieve la necesidad de completarla con el acuerdo de cesión del aprovechamiento municipal.

Pero el Ayuntamiento, puede intervenir directamente en una transferencia de aprovechamiento como interesado y no simplemente como Administración Urbanística, si previamente ha patrimonializado suelos con destino a usos públicos mediante adquisición onerosa. En estos casos, el Ayuntamiento adquiere la titularidad de una parcela con aprovechamientos subjetivos que no puede materializar y puede realizar el acuerdo de transferencias igual que si uno realizado entre los particulares.

Si la TAU se realiza por el Ayuntamiento, en realidad, habrá que distinguir un doble contenido de actos jurídicos de transmisión de aprovechamientos, en el que se diferencia una transferencia y una cesión: 
a) una cesión del aprovechamiento municipal en cuanto Administración Urbanística, normalmente mediante compensación económica. No se transfiere ningún aprovechamiento de una finca a otra: sólo se transmite la parte del aprovechamiento municipal que se genere en la parcela edificable. Es el aprovechamiento correspondiente al tramo que se sitúa entre el $90 \%$ y el $100 \%$ del AM.

Es importante aclarar que la transmisión del $10 \%$ de excesos de aprovechamientos, no es técnicamente una transferencia de aprovechamiento. En este caso, la transmisión que se produce es la cesión a favor del titular de la parcela de los derechos que tiene la Administración en la misma parcela de la que se deriva su participación en las plusvalías derivadas del planeamiento. Por ello, no se produce transferencia de aprovechamientos entre parcelas, sino la cesión del aprovechamiento que le corresponde a la Administración en la misma parcela en la que se origina el exceso de aprovechamiento.

b) Una verdadera transferencia, ya sea mediante acuerdo de distribución o de cesión

Hay que tener presente que la valoración de la cesión del 10\% AM correspondiente a la Administración se valora conforme a la finca que lo soporta. Y además, se trata de un aprovechamiento que se entrega libre de cargas urbanísticas, por lo que la valoración de ese $10 \%$ es superior a la valoración del tramo correspondiente a los excesos sobre el aprovechamiento medio.

\subsection{La forma y el procedimiento de la transferencia}

Conforme a lo dispuesto en el art.62.2 LOUA el acuerdo de transferencia debe formalizarse en escritura pública, con planos adjuntos expresivos de la localización y dimensiones de las parcelas implicadas.

\section{El acuerdo entre las partes de la transferencia debe contener:}

a) La identificación de las parcelas que intervienen: la transmitente y la receptora de aprovechamientos

b) La determinación de los aprovechamientos objetivos y subjetivos que corresponde a cada parcela interviniente.

c) La cuantificación del aprovechamiento que se transfiere.

d) La determinación de si la transferencia consiste en una cesión o una distribución. 
e) las compensaciones económicas que correspondan.

f) La descripción del estado de aprovechamientos urbanísticos resultantes de cada parcela.

g) La cesión de la parcela transmitente a la Administración, en el caso de que esté destinada a usos públicos.

En el apartado 2 se establece la necesidad de la aprobación municipal para la validez de las Transferencias: "La transferencia de aprovechamiento deberá ser aprobada por el Municipio"

La LOUA no indica el procedimiento de aprobación, dejando pasar la oportunidad de su concreción porque el apartado 4 vuelve sobre esta cuestión, pero con un contenido que nada añade a lo previsto en el apartado 2. Así dispone el apartado 4: "Las transferencias de aprovechamientos convenidas por los propietarios para el cumplimiento de sus deberes y obligaciones urbanísticos y el cumplimiento del principio de justa distribución de beneficios y cargas, se aprobarán y tramitarán por la Administración actuante conforme a lo dispuesto en los números anteriores".

Puede entenderse que la tramitación únicamente contendría un acuerdo de aprobación. Pero también podría interpretarse que se aplicarían de forma supletoria las normas del procedimiento de aprobación de la reparcelación voluntaria (art.104.2), dada su similitud, lo que exigiría un trámite de información pública de 20 días.

\subsection{Actividad fiscalizadora de la Administración}

La Administración controla en el momento de la edificación el ajuste entre los aprovechamientos subjetivos y objetivos, y además controla los acuerdos de transferencias de aprovechamientos al requerirse la aprobación municipal.

En la solicitud de licencia, se controlan los siguientes aspectos, relacionados con las TAU:

1. Que se trate de un suelo urbano no consolidado

2. Que se trate de un ámbito en el que no esté delimitado ni se prevea la delimitación de unidades de ejecución.

3. Que venga previsto en el planeamiento general la aplicación de las TAU, estableciendo la delimitación del Área de Reparto y determinando el aprovechamiento medio.

4. Que cuente con la ordenación pormenorizada establecida directamente por el Plan General o, en otro caso, que se encuentre apro- 
bado definitivamente el Plan Especial si se trata de un área de reforma interior con ordenación pormenorizada diferida en el planeamiento general, o incluso del Estudio de Detalle. Al tratarse de una técnica de ejecución urbanística, se encuentra vinculada a lo dispuesto en el art.96.1.b) de la LOUA (presupuesto de cualquier actividad de ejecución) que requiere la previa aprobación del instrumento de planeamiento idóneo dirigido a establecer la ordenación pormenorizada para el desarrollo de la actividad de ejecución.

5. Si se han formalizado o no las transferencias y la cesión del aprovechamiento municipal.

En el acto de aprobación la Administración realiza una labor fiscalizadora y controladora de las Transferencias: la clarificación de los aprovechamientos que intervienen, su correspondencia y equivalencia. A parte de garantizar, la obtención gratuita de la finca con aprovechamiento lucrativos nulos por estar destinada a usos públicos, así como la materialización o compensación de su derecho a la participación en las plusvalías.

Por eso, no puede admitirse la plena libertad de los acuerdos de TAU entre los particulares, porque siempre es preciso realizar el ajuste de los aprovechamientos correspondientes al Ayuntamiento.

La LOUA ha limitado el acuerdo privado de transferencias de aprovechamientos, y sólo tiene efectos administrativos el que es aprobado por la propia Administración.

Según Bassolls Comas: "Estamos ante negocios jurídicos de carácter civil que tienen por objeto la transmisión, el pase de un patrimonio a otro, de determinados bienes. Una actividad hasta cierto punto coordinada, controlada y vigilada por la Administración, pero que no por ello deja de ser esencialmente privada”.

La actividad fiscalizadora tiene su última expresión en la necesidad de inscripción de las TAU en un registro especial de naturaleza administrativa. El artículo 65 de la LOUA regula el Registro de Transferencia de Aprovechamientos.

En realidad, este Registro cumple funciones más amplias que las de un Registro de Transferencias de Aprovechamientos en sentido exclusivo, pues se deben inscribir los acuerdos de aprobación de las reservas de aprovechamiento. 
No puede inscribirse en el Registro de TAU si no se acredita la titularidad de la parcela/s a la que la transferencia se refiera. Si existen cargas es precisa la conformidad de aquéllos a cuyo favor figure (los titulares de los derechos que gravan la finca objeto de transferencia).

La LOUA no exige que las TAU se realicen entre fincas pertenecientes a la misma Área de Reparto, pero la lógica del sistema exigiría esta pertenencia unitaria.

\subsection{Actividad intermediadora de la Administración en las TAU}

La Administración puede facilitar el ajuste de los aprovechamientos y por tanto, de las transferencias. Así, de forma previa, puede identificar, para general conocimiento, los aprovechamientos que se pueden transferir o ceder. Pero fundamentalmente su actividad intermediadora se concentrará en generar aprovechamientos subjetivos que pueden aplicarse a las TAU mediante la previa adquisición de los terrenos calificados para usos públicos de forma onerosa.

De forma accesoria la Administración puede facilitar la edificación de las parcelas con aprovechamientos urbanísticos excedentarios mediante compensaciones económicas sustitutivas. Así se reconoce en el art.64.1 de la LOUA, en defecto de acuerdo de transferencia o reserva. Esta es una alternativa que incorpora la LOUA, si bien puede generar efectos perturbadores si la Administración no procede de forma inmediata a adscribir esos ingresos para la adquisición de los suelos dotacionales y procede a iniciar los procedimientos para su efectiva adquisición.

$\mathrm{Y}$ es que, en defecto de estos acuerdos de transferencias, el aprovechamiento subjetivo no materializable debe ser expropiado por la Administración en el caso de parcela con destino de usos públicos; de igual forma, deberá ser expropiado o indemnizado el aprovechamiento subjetivo no materializable en el supuesto de parcela con aprovechamiento real inferior.

\subsection{Sobre el carácter forzoso o voluntario de las TAU}

De una primera interpretación podría deducirse de lo dispuesto en el artículo 62.1 de la LOUA que las transferencias son voluntarias, al establecer que "los propietarios de una parcela o solar pueden transferir el aprovechamiento".

Ahora bien, la configuración de las transferencias como voluntarias supone asumir el riesgo de que finalmente la Administración no obtenga de for- 
ma gratuita los equipamientos del suelo urbano no consolidado, y sin embargo, tenga necesariamente que compensarlos a sus propietarios. Y es que, los propietarios de parcelas con aprovechamiento nulo o con aprovechamientos inferiores al 90\% del aprovechamiento medio del Área de reparto, tienen derecho a exigir al Municipio la compensación económica equivalente.

En efecto, los propietarios de parcelas con aprovechamiento objetivo nulo (destinadas a usos públicos) pueden forzar al Ayuntamiento a la expropiación (art.140.1 de la LOUA).

Un desfase en la aplicación de las TAU con retrasos por parte de los propietarios con parcelas con aprovechamiento objetivo superior puede provocar que se rompa en pedazos la estrategia de gestión planteada de adquisición gratuita sin desembolsos previos como consecuencia del ejercicio de la facultad reconocida en el art.140.1 a los propietarios de parcelas calificadas con usos públicos.

Por tanto, no puede hablarse de voluntariedad en términos generales de las TAU, porque no puede quedar en manos de un propietario el cumplimiento de los deberes de cesión (recuperación de plusvalías y de los excesos) y equidistribución. Siempre existe la obligación de ajustar los aprovechamientos y adquirir los necesarios bien sea materialmente o mediante compensación económica sustitutiva.

Por ello, las TAU son obligatorias para el propietario con excedentes de aprovechamientos y potestativas para el propietario con parcelas con aprovechamiento deficitario o nulo, que tiene la alternativa de la expropiación o de la reserva de aprovechamientos, o incluso de la ocupación directa. La única alternativa que tendrían los propietarios con excedentes es solicitar al Ayuntamiento la cesión del aprovechamiento excedentario.

No existe un deber a transferir por parte del propietario con defectos de aprovechamientos reales ("los propietarios pueden transferir"), pero sí puede ser objeto de expropiación por parte de la Administración, quien se subrogaría en esos derechos, y se produciría con posterioridad el ajuste necesario.

\subsection{Las Transferencias y el Registro de la Propiedad}

El art.1.3 del RD 1093/1997, de 4 de julio señala que serán inscribibles los actos de transferencia del aprovechamiento urbanístico y ello, incluso cuando den lugar a un derecho separado del suelo. 
Por tanto el aprovechamiento urbanístico es susceptible de tráfico jurídico y es considerado en el citado RD como una figura especial disgregada del suelo.

La disociación del contenido del derecho de propiedad inmobiliaria se materializa en el Registro de la Propiedad al permitir inscribirse el aprovechamiento como finca independiente. Los efectos que se derivan son:

a) la adquisición del derecho al aprovechamiento urbanístico se hace constar por nota marginal en la finca de la que forma parte.

b) la transferencia de aprovechamientos entre distintas fincas es inscribible.

c) se produce la apertura transitoria de un folio independiente cuando no pueden inscribirse las unidades de aprovechamiento en el folio correspondiente a la finca de que proceden y se extingue cuando se puede inscribir a favor del titular del aprovechamiento la finca de resultado.

\section{CONCLUSIONES SOBRE LAS TRANSFERENCIAS DE APROVE- CHAMIENTOS URBANÍSTICOS DE LA LOUA}

$1^{a}$. La técnica de Transferencias de Aprovechamientos Urbanísticos definida en la Ley andaluza 7/2002 tiene un alcance limitado (en cuanto a la categoría de suelo), sólo son de aplicación cuando lo prevea el Plan General en el suelo urbano no consolidado en el que se delimite un Área de Reparto y no se delimite unidad de ejecución.

2a․ Se excluye su aplicación en el suelo urbano consolidado.

$3^{\text {a }}$. La virtualidad que en la legislación vinculada al Texto Refundido de la Ley del Suelo de 1992 tenían las TAU de apoyo a las políticas de rehabilitación, ha desaparecido, por quedar excluida su aplicación en el suelo urbano consolidado (y por regla general los terrenos del conjunto histórico, salvo en las operaciones puntuales de reforma interior, tienen el carácter de suelo urbano consolidado).

$4^{\mathrm{a}}$. Las TAU de la LOUA no aseguran que los propietarios del suelo urbano no consolidado cumplimenten todos los deberes, sino sólo de algunos de ellos, el resto dependerá del grado de urbanización. La Transferencia permite ejecutar los deberes de cesión y distribución, pero no el deber de urbanizar, que se garantiza también en el acto del otorgamiento de licencia mediante los compromisos oportunos para su ejecución simultánea a la edificación. 
$5^{\text {a }}$. No pueden identificarse con las TAU establecidas por el TRLS 92 que afectaban a todo el suelo urbano.

$6^{\text {a }}$. No pueden identificarse con las TAU deducidas de la legislación vinculada al TRLS 76.

7a․ No queda garantizado que finalice el proceso de transferencia de aprovechamientos a lo largo de la vida del Plan, salvo que se establezca un plazo de edificación, que afecte incluso a las parcelas ya edificadas para su sustitución de acuerdo con las nuevas posibilidades edificatorias del Plan.

$8^{\text {a }}$.Las TAU ponen de relieve que el aprovechamiento urbanístico es un derecho real patrimonializable con independencia del suelo.

Jerez a 29 de junio de 2004 . 